\title{
Sustainability Target Pyramid A Synthesis of Sustainability and Information System
}

\author{
Tabassom Hashemi Farzad ${ }^{1, *}$, Horst Junker ${ }^{2}$ \\ ${ }^{1}$ Department of Computing Science, C.V.O University of Oldenburg, Germany \\ ${ }^{2}$ Institute for Information Processing, IMBC GmbH, Germany
}

Copyright (C) 2015 by authors, all rights reserved. Authors agree that this article remains permanently open access under the terms of the Creative Commons Attribution License 4.0 International License

\begin{abstract}
The businesses have a critical role in moving the society toward sustainability. The fast changing and dynamic global business environment requires firms to be more flexible to quickly adapt and respond to market changes. Among the forces that drive changes, requirements for corporate responsibility and sustainability are getting more urgent. During such difficult time as this economic downturn, companies are faced with hard choices to survive. Research has acknowledged that addressing sustainability issues is critical to the long-term existence and thriving of companies. The concept of sustainability makes it necessary that besides the economic categories and the operational environment protection, it should be considered the social effects of company in management actions. Sustainability business oriented can be realized through developing a corporate target pyramid in enterprise. Such pyramid will help organizations to shape their targets in accepting social, environmental and economic responsibilities. The current research tries to review the research background done till now and depict a perspective of an integrated target pyramid for both scholars and managers. Furthermore, this paper has a holistic look toward the concept of sustainable information system.
\end{abstract}

Keywords Sustainability, Sustainability Information Systems, Information Management, Target System

\section{Introduction and Research Background}

Sustainability should be seen as a concrete, integrated and comprehensive concept, that despite consisting three different dimensions but it represent a unified notion. The question is how companies can integrate sustainability in their daily business operation. Schaltegger [15] stated that four sustainability challenges arise in the companies regarding sustainable development. Ecological challenge which improve the eco efficiency, Social challenge which deal with improving the Socio-effectiveness, Economic challenge regarding environmental and social management which improve the eco-efficiency and / or socio-efficiency and finally integration challenge bringing together the three aforementioned challenges and integration of environmental and social management in the conventional economically oriented management. Hall [8] noted the emerging research associated with sustainable development and entrepreneurship. Entrepreneurship is one of the major efforts for sustainable products and processes, play important role for many social and environmental problems. Hall overviewed of sustainable development and the role of entrepreneurship and outline recent contributions exploring this role. Seuring and Müller [16] investigated a comprehensive review on conceptual framework for sustainable supply chain management. Byggeth [2] stated a method for sustainable product development based on a modular system of guiding questions. Erek et al. (2009) elaborate on all three sustainability aspects in relation to IS organizations, although the data collection and analysis are primarily focused on the environmental aspect. He counted some advantages of sustainable information system such as achieve transparency of the suppliers' products and services, minimize the consumption of resources while maximizing the output, meet internal and external (stakeholder) demands, and recycle and reuse materials. Some scholars discuss what contributes to a more sustainable future, e.g., in terms of the social aspects brought forward by Web 2.0, but the overall theme is yet again the environmental aspect [1]. Long [12] has developed a target system shown how ecologically and economically targets can be integrated in in -house logistic. In another study, Wittstruck and Teuteberg [17] refers to reduce material and energy consumption, use renewable energy sources and create save and healthy working environments as the main objectives of sustainability information system. While limited academic research has investigated the relationship between sustainability and 
information system, practitioners' literature has been increasingly paying more attention to the role of information system in enhancing and maintaining sustainability in business processes. Caldelli and Parmigiani [3] tried to evaluate the degree to which companies' information systems correspond to needs determined by the objectives of sustainability the company imposes on itself, and did it through a case study in Italy. Chen [4] considered a question about how information systems can help organizations develop ecological sustainability. Their findings from applying institutional theory indicated that information system can be leveraged to achieve eco-efficiency, eco-equity and eco-effectiveness through automating, informating, and transforming organizations. Upward informating system is often associated with enhanced organizational control, as it informs management in almost all aspects of business operations.

While authors of the mentioned studies in the research background were tried to discuss the role of information system in sustainability, there is still a gap in some areas. First, the social dimension of sustainability is not studied well in the literature, and the social sustainability is a vague construct in this way. The literatures often concentrated on the environmental aspect of sustainability and neglect to study the social concerns and the inter-linkage between social dimension with environmental and economic aspects of sustainability. Regarding this issue, the first question that must be addressed in assessing the social sustainability of a corporation is which social impacts or indicators should be considered? In response to the above question, companies should be evaluated in terms of their social impacts for example on their stakeholders including owners, investors, employees, suppliers, customers and even a society. This paper intends to investigate corporate social and ecological targets in three levels of management and embed these targets group in daily operation of organization.

Second, integration between targets in each dimension of the sustainability was not studied in the previous researches. Integration of the sustainability dimensions is a critical issue in sustainability literature. So, the integration concept and process is not as obvious as the other issues in sustainability literature. Integration in sustainability assessment become to a great concerns, because such assessments must bring together a wide variety of issues and topics. An integrated assessment for sustainability involves a comprehensive consideration of the economic, social, environmental, and other relevant aspects of the entity, including the relationships among all these factors. Some studies claimed that integrative approach helps to identify win-win solutions that integrate all three dimensions of sustainability. While lack of integration resulted to misunderstanding of sustainability and resulted to confusing assessment report of sustainability, integration allows better identification and documentation of indirect and synergistic effects which result from linkages among environmental, economic and social impacts which otherwise might be overlooked in separate, more specialized assessments [13].
Third authors did not provide empirical evidence about the influence of information system on sustainability, therefore the question about how information system could support sustainability would be an interactive research question. The attempts of the scholars to discuss sustainability information system focus on social dimension of sustainability.

In the proposed research, it is tried to fill these gaps, and to provide implication for both of scholars and managers.

\section{Research Question and Objectives}

The relationship between sustainability and information system will be investigated. The focal point of study is about the relationship between information system and sustainability into a concept which it called Sustainability Information System (SIS). So, the main question of the research would be stated as follow:

\section{How information system could support sustainability?}

To answer this question, in the first phase, a target pyramid will be developed which could be used to evaluate the concept of sustainability (Environmental, Social and Economical), regarding the different level of analysis (Strategic, Tactical and Operational) and information system functions and attributes (Information Transfer, Information Processing, Information Storage) $[12,14,7]$. This pyramid enables the researcher to identify the targets for main functions of information system that could support each dimension of sustainability in different level of analysis. Also, this pyramid helps the researcher to compare targets in each dimension of sustainability, and integrate them in a framework which could be applied to the information system context. The integration could enlighten the internal relationship between sustainability dimensions and describe that whether their relationships are complementary, conflicting, or neutral. On the other hand, integration will help researcher to develop a target pyramid which contains coordinated criteria for formulating the framework of sustainability information system. So, such pyramid led to identify the main attributes of the information system that support sustainability, and could be regarded as the primary answer to the main research question. In addition, this pyramid will clarify the theoretical attributes of sustainability information system (SIS) as a kind of information system that is compatible with sustainability concept. Then, in the second phase of the research, this pyramid will be applied to a specific case, and it will be tested from the viewpoints of comprehensiveness, innovation, feasibility, accuracy, rationality, and applicability. The main question of the research is quite effective as it will mainly help in identifying that how information system would support sustainability, how it integrated with social, environmental and economical dimensions of sustainability, and what is the optimum architecture of sustainability information system. Investigation about the main question of the research 
resulted to find answer about the below secondary purpose:

- What are the social attributes of sustainability, regarding the information system field of study?

- How far is it possible to integrate these attributes?

- What are the main attributes of sustainability information system?

Finding an answer for the mentioned question could complete the results of the research, fill the gap of the current theory, and provide directions for future research on sustainability information system from the theoretical perspective.

\section{Proposed Study}

Sustainability strategic information management can be realized throughout five steps of development of a common multi-dimensional sustainability target system ,situation analysis, target planning (enterprise specific sustainability target system adjustment), strategy development, information system planning.(11). Figure 1 illustrates the overall the fundamental tasks of strategic information management, which lead to plan for a sustainability information system.

Target pyramid plays a main role as an operational planning, management and control tool, therefore it is necessary that the targets are structured, ordered, fully known to all stakeholders in the company, and be transparent and there exist no spaces, contradictions and uncertainties among the targets [9].

Sustainability target pyramid can be performed throughout developing the organization enablers including leadership, stakeholder, policy, organizational resources and processes. It will help organizations to measure their integrated capabilities in accepting social, environmental and economic responsibilities. It will form with the aim of improving and integrating all of the organizational criteria and tries to assess the five mentioned criteria and consequently enhance the environmental, social and economic results. (Fig. 2)

Since in current research, developing the target system is groundwork of realization of sustainability concept, the next part would be allocated to discussing target system and its component.

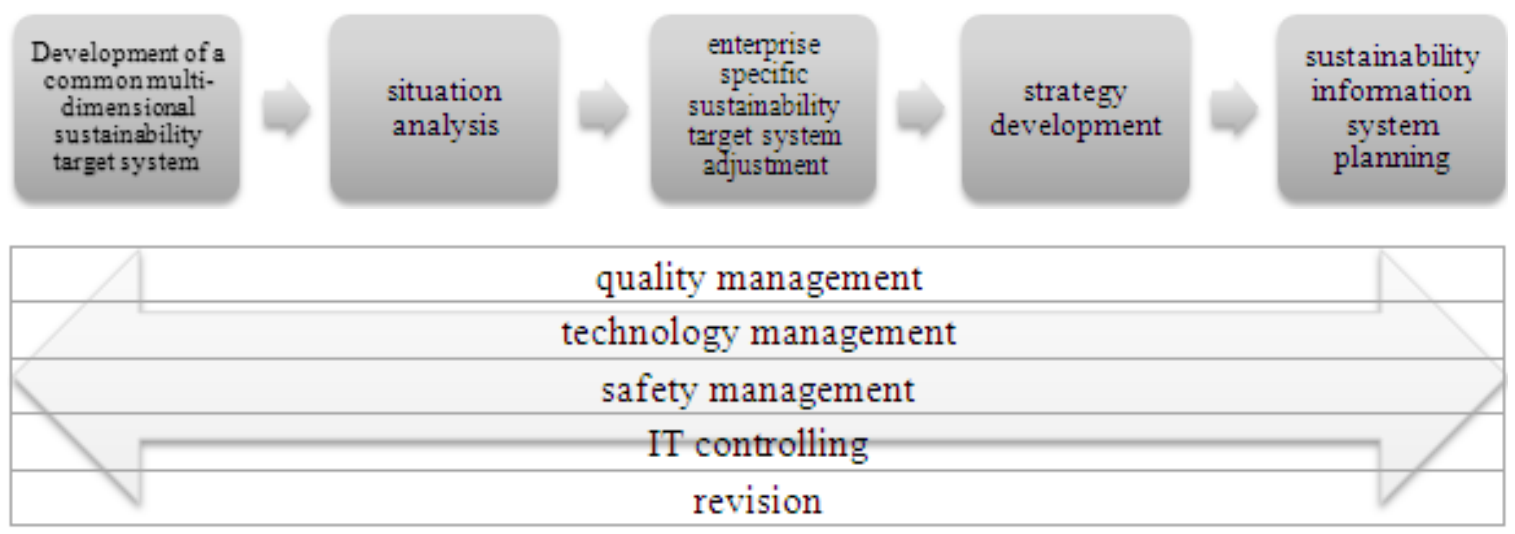

Figure 1. Strategic sustainability information management

\section{Enablers}

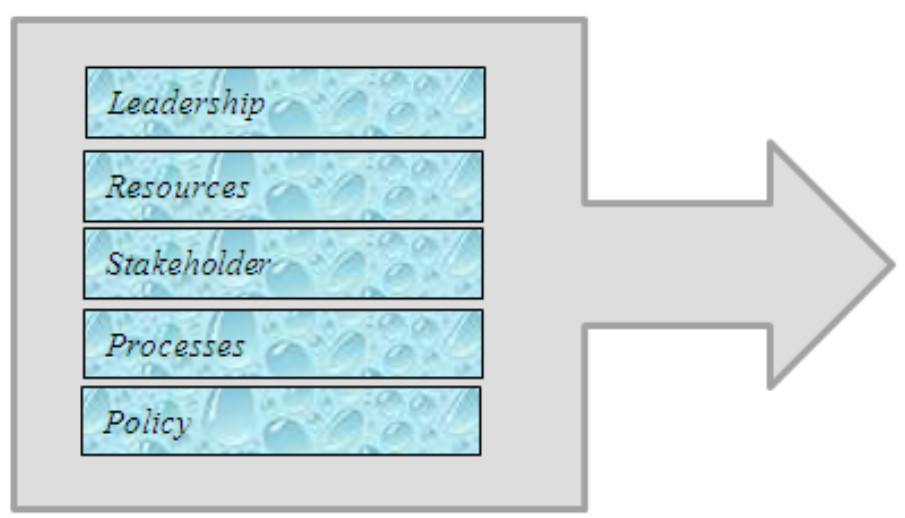

\section{Sustainabality results}

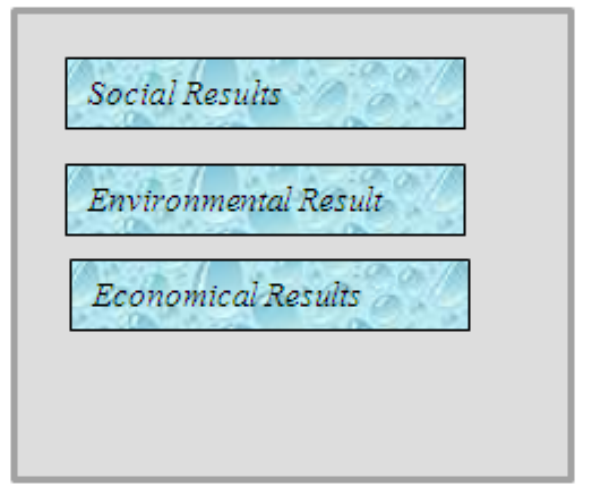

Figure 2. Criteria relationship 


\section{Targets and Targets System}

Targets describe the emerging states of reality, which can be achieved by certain measures or solutions". The formulation of corporate targets and their concretizations taking into account different stakeholders are an important task in management since targets are key command variables, "on which future action can be measured and optimal decisions can be taken". Basically by developing target systems have to solve the important targets conflicts [12].

A target system consists of a group of targets that targets situated in a particular area and functionally related. Such targets are so related that their destruction will produce some particular effect desired by the attacker.

To develop a target pyramid sustainability-oriented, it is necessary first to order the targets in a meaningful manner and define the upper Targets for ecological and economic dimensions as well as social dimension separately. Subsequently, the middle targets (tactical) and sub targets (operative) are derived from top targets (Strategic). The top targets are increasingly operationalized with the help of sub-targets [12].

The development of a target pyramid in practice requires the following steps:

- To build target catalog

- To build the target system

- To operationalize the target system

- Weighting System [10].

\section{Methodology}

Finding and selection of company relevant targets constitutes the main problem in developing a consistent target system. This research conduct based on deductive approach. A deductive research process has its starting point in the theory. The researcher continues with formulation of hypotheses, which are supposed to be tested with the collected data and finally confirmed or not. A deductive approach starts out from a general idea and results in more specific concept. The literatures on concept of sustainability are theoretical foundations which current research is based on, and researcher will use them to answer the main question of the research and to develop a framework for sustainability target pyramid. It is notable that while this research is deductive one, the scientific norm of logical reasoning provides a two-way bridge between theory and research. In practice, this typically involves alternating between deduction and induction approaches as well as necessary. Current research has two phases. The first phase is the development of target pyramid which is the basis of sustainability information system framework, and the second be devoted to the information system concept. The research method for development of target pyramid is chosen to be Delphi method. This method is an expert survey that has proven a popular tool in information systems research for identifying and prioritizing complex issues for managerial decision-making.

\section{Research Supposed Results}

As mentioned in the research objectives, current research led to find an answer for the question of "How information system could support sustainability?". Finding an answer for this question resulted to determine the criteria of sustainability information system which could be used as a pattern for comparing information systems regarding with the concept of sustainability. Another considerable result of this research is about the integrated target pyramid that will be the basis of formulation and development of sustainability information system. The integration could enlighten the internal relationship between sustainability dimensions and describe that whether their relationships are complementary, conflicting, or neutral. In addition, this integration provides a valuable insight about the ties between dimensions of sustainability and strategic, tactical or operative level of analyses. Discussing the integration is an important part of this study since that the development of sustainability information system needs a set of coordinated and integrated targets which do not have conflict in nature and have synergy to build a sustainable framework.

\section{REFERENCES}

[1] Bengtsson, F., \& Agerfalk, P. J. (2011). Information technology as a change actant in sustainability innovation: Insights from Uppsala. The Journal of Strategic Information Systems, 20(1), Pp. 96-112.

[2] Byggeth, S., Broman, G., \& Robèrt, K.H. (2007).A method for sustainable product development based on a modular system of guiding questions. Journal of Cleaner Production, 15(1), $1-11$.

[3] Caldelli, A., \& Parmigiani, M. L. (2004). Management information system-a tool for corporate sustainability. Journal of Business Ethics, 55(2), 159-171.

[4] Chen, A. J., Boudreau, M. C., \& Watson, R. T. (2008). Information systems and ecological sustainability. Journal of Systems and Information Technology, 10(3), 186-201.

[5] Dao, V., Langella, I., \& Carbo, J. (2011). From green to sustainability: Information Technology and an integrated sustainability framework. The Journal of Strategic Information Systems, 20(1), 63-79.

[6] Erek, K., Schmidt, N.H., Zarnekow, R., \& Kolbe, L.M. (2009). Sustainability in information systems: assortment of current practices in IS organizations. AMCIS 2009 Proceedings, Available at: http://aisel. aisnet. org/amcis2009/123, San Francisco, USA

[7] Florian, S. \& Frank, T. (2013). Towards a conceptual framework for life cycle assessment in sustainable information systems management. Proceedings of the $21 \mathrm{st}$ European Conference on Information Systems. Utrecht, 
Netherlands.

[8] Hall, J.K., Daneke, G.A., \& Lenox, M.J. (2010).Sustainable development and entrepreneurship: Past contributions and future directions. Journal of Business Venturing, 25(5), 439-448.

[9] Hopfenbeck W (1992) Allgemeine Betriebswirtschafts- und Managementlehre. Das Untenehmen im Spannungsfeld zwischen ökonomischen, sozialen und ökologischen Interessen, 6. Auflage. Landsberg/Lech

[10] Junker, H. Marx Gómez, J.Lang, C.(2010) Betriebliches Umwelt und Nachhaltigkeitsmanagement, MKWI

[11] J Junker,H., Farzad, T., (2015). Toward sustainability information system . ELSEVIER, Procedia Computer Science. 64, 1130-1139

[12] Long, C. (2006). Konzeption eines Referenzmodells für betriebliche Umweltinformationssysteme im Bereich der innerbetrieblichen Logistik.Otto-von-Guericke-Universität Magdeburg

[13] Morrison-Saunders, A., \& Therivel, R. (2006). Sustainability integration and assessment. Journal of Environmental Assessment Policy and Management, 8(3), 281-298
[14] Pal, S. K. (2008). 21st Century Information Technology Revolution. Ubiquity, June Issue, DOI: $10.1145 / 1399616.1399619$

[15] Schaltegger, S., Herzig, C., Kleiber, O., Klinke, T., Müller, J. (2007): Nachhaltigkeitsmanagement in Unternehmen , BMU/econsense/CSM (Hrsg)

[16] Seuring, S., \& Müller, M. (2008). From a literature review to a conceptual framework for sustainable supply chain management. Journal of Cleaner Production, 16(15), $1699-1710$.

[17] Wittstruck, D., \& Teuteberg, F. (2011). Development and simulation of a balanced scorecard for sustainable supply chain management-a system dynamics approach. In Proceedings of the $10^{\text {th }}$ International Conference on Wirtschaftsinformatik. Loos, P., Nüttgens, M. (Eds.), Zurich, 332-341.

[18] International Conference on Wirtschaftsinformatik. Loos, P., Nüttgens, M. (Eds.), Zurich, (pp. 332-341).

[19] Wöhe G (2005) Einführung in die Allgemeine Betriebswirtschaftlehre, 22. Auflage. München. 